\title{
Evidence of Upwelling along Peninsular Malaysia during Southwest Monsoon
}

\author{
Mohd Fadzil Akhir¹, Farshid Daryabor², Mohd Lokman Husain ${ }^{3}$, Fredolin Tangang4, \\ Fangli Qiao5 \\ ${ }^{1}$ Institute of Oceanography and Environment, Universiti Malaysia Terengganu, Kuala Terengganu, Malaysia \\ ${ }^{2}$ Institute of Ocean and Earth Science, University of Malaya, Kuala Lumpur, Malaysia \\ ${ }^{3}$ School of Marine and Environmental Science, Universiti Malaysia Terengganu, Kuala Terengganu, Malaysia \\ ${ }^{4}$ Faculty of Science and Technology, National University of Malaysia, Bangi, Malaysia \\ ${ }^{5}$ First Institute of Oceanography, Qingdao, China \\ Email: $\underline{\text { madzil@umt.edu.my }}$
}

Received 2 June 2015; accepted 4 July 2015; published 7 July 2015

Copyright (C 2015 by authors and Scientific Research Publishing Inc.

This work is licensed under the Creative Commons Attribution International License (CC BY).

http://creativecommons.org/licenses/by/4.0/

(c) (7) Open Access

\section{Abstract}

Upwelling off the east coast of Peninsular Malaysia (PM) was detected from recent cruise data collected during the southwest monsoon. Thermocline lifting was observed at $104^{\circ} \mathrm{E}$ from a number of parallel transects. To confirm the presence of upwelling, satellite remote sensing data were used, and numerical model experiments were conducted. A cooler sea-surface temperature along the coast was spotted from both in-situ and satellite data while upward movement from the model agreed with field data. The southwesterly wind that blows along PM from June to September is believed to be the important mechanism that contributed to this upwelling through an Ekman dynamics process.

\section{Keywords}

South China Sea, Upwelling, Peninsular Malaysia, Southwest Monsoon, Numerical Model

\section{Introduction}

Most coastal upwelling regions are governed by classical wind-driven Ekman dynamics. In the semi-enclosed basin of the South China Sea (SCS), a number of these upwelling systems are found along the western boundary. It has been known that coastal upwelling occurs during the summer along the coast of Vietnam [1]-[3] and near Hainan Island [4] [5].With the summer monsoon being an important force in the region, southwesterly upwelling favorable wind provided the perfect setting for such features to occur. One such place is the east coast of 
Peninsular Malaysia (PM). Unlike the central and northern SCS, there have been very few published reports of upwelling off PM, i.e. [6] [7]. These early studies, however, covered a localized area, and the descriptions of the upwelling were brief. The available research so far are unable to draw a clear spatial coverage of upwelling presence along PM coast, which shows that the understanding of upwelling system in the region needs significant attention. Nevertheless, looking at the dynamic potential of Ekman dynamics presence during southwest monsoon, hypothetically the scale of upwelling formation along the coast can be relatively large given the length of the meridional coastline governed by PM.

The current circulation system within SCS main basins is cyclonic in winter and anti-cyclonic in summer. This current pattern is mainly influenced by seasonal changes in monsoon wind. During summer, southwesterly wind is dominant along the western coast of SCS, especially near PM and the Vietnam coast, which flows northeastward. This seasonal wind that is favorable for upwelling formation and study of the Vietnam coast found that Ekman transport plays an important role in inducing coastal upwelling [2]. The similar wind settings are shared by both Vietnam coast and east coast of PM. Ekman transport upwelling theory is applicable to both areas but with one contrasting point; Vietnam's narrow continental shelf and steep slope allow upwelling to be intensified [8] while the PM coast is a broad shallow shelf.

Since the earlier publications of schematic surface current charts based on observed drift current data by [9] and the cruise report by [10], field observation near the study area has been lacking, and the understanding of the southern SCS current circulation is also limited. Nevertheless, a cruise with the RV SEAFDEC during 19951996 covering the area from the Gulf of Thailand to the southernmost tip of Peninsular Malaysia provided the first insights of a surface cold water patch along the coast [11]. Reference [11] reported a value of $28.6^{\circ} \mathrm{C}$ surface temperature at $4^{\circ} \mathrm{N}$. The presence of thermocline/halocline lifting can also be observed from the alongshore transect in both temperature and salinity at $104^{\circ} \mathrm{E}$. Although there is no upwelling mentioned in any of these papers, the data provided are consistent with what was found in our recent in-situ data. In terms of circulation, a study by [12] using in-situ data showed that the upper-layer circulation in the southern SCS is dominated by an anticyclone gyre during summer. This is consistent with the finding of numerical model outputs, which suggested a high intensity current along PM moving northward during the southwest monsoon (June-August) [13] [14]. This limited information has at least shown that the oceanographic setting along the PM east coast is favorable for wind-driven Ekman upwelling during the southwest monsoon.

In this paper, initial evidence for the upwelling off the PM east coast during the southwest monsoon is presented by providing analysis from field observation and 10 years of satellite-derived sea-surface temperatures (SST). Furthermore, aspects of the upwelling features will be discussed based on numerical model output.

\section{Methods}

\subsection{Field Data}

A cruise onboard the KL Cermin (KLC02/2012) was conducted between 27/6/2012 and 1/7/2012. It was a collaboration between Malaysia and China to collect multi-disciplinary data at the east coast of PM. The study area spans from approximately $5.0^{\circ} \mathrm{N}-6.3^{\circ} \mathrm{N}$ and $103.3^{\circ} \mathrm{E}-105.6^{\circ} \mathrm{E}$. Data collection was organized into four transects of 25 stations (Figure 1). At each station, the vertical profiles of temperature and salinity were measured with a calibrated SBE Plus19v2 CTD, with the rosette water sampler attached and cast from shipboard to the bottom at a $4 \mathrm{~Hz}$ sampling rate.

Satellite-derived SST from Moderate Resolution Imaging Spectroradiometer (MODIS) Aqua satellite observations was used to analyze the upwelling signals, as a supplement to the in-situ data. The SST images used in this paper are standard level-3 (4 km) composites averaged from 2002 to 2012 and obtained from the Oceancolor Web site.

\subsection{Numerical Model}

A Regional Ocean Modeling System (ROMS) was used to simulate the three-dimensional circulation in the southern SCS. It was set up in a two-domain configuration: the coarse grid model domain covering $20^{\circ} \mathrm{S}-30^{\circ} \mathrm{N}$ and $90^{\circ} \mathrm{E}-140^{\circ} \mathrm{E}$, which encompasses the Indian and Pacific oceans with a horizontal resolution of $0.5^{\circ} \times 0.5^{\circ}$ $(\sim 50 \mathrm{~km})$ and 30 vertical S-levels, and the fine grid domain $\left(2^{\circ} \mathrm{S}-15^{\circ} \mathrm{N}\right.$ and $\left.97^{\circ} \mathrm{E}-117^{\circ} \mathrm{E}\right)$, which has $0.08^{\circ} \times$ $0.08^{\circ}$ horizontal spacing $(\sim 9 \mathrm{~km})$ and the same 30 vertical S-levels. The focus of this study is the major features 


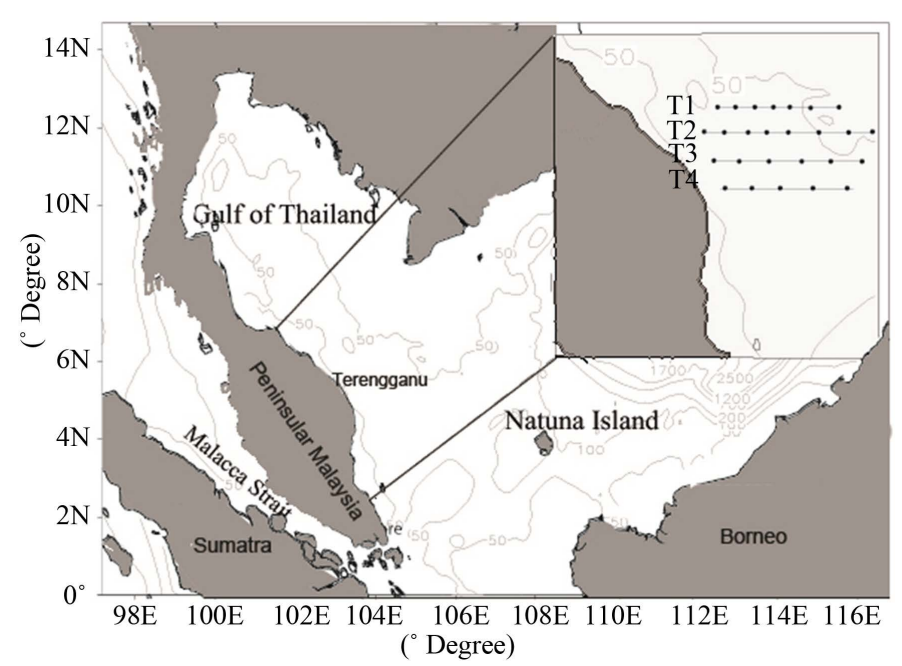

Figure 1. Map of the study area. Transects and stations from KLC02/2012 are shown in the inset.

of coastal current and the temperature distribution along the east coast of PM, which is covered by the fine grid domain.

The bathymetry used in both domains was based on ETOPO2 at $3.7 \mathrm{~km}$ horizontal resolution [15]. Furthermore, the topography was also smoothed with a slope parameter of less than 0.25 to avoid a pressure gradient error [16]. The surface forcing fields of the model (i.e., wind stress, net heat and surface freshwater fluxes) were obtained from the Comprehensive Ocean-Atmosphere Data Set (COADS) [17]. The long-wave radiation was computed internally using the method described by [18]. The incoming short-wave radiation was computed from the albedo formulation using the global equation to resolve the daily heating cycle in the model. In addition, the net heat flux used short-wave radiation as a secondary surface forced into the model to compute surface radiative buoyancy flux in the K-profile parameterization (KPP) and heat penetration in the water column [19].

The model was integrated for six years using the climatological monthly-mean salinity and temperature of the World Ocean Atlas 2005 (WOA 2005) [20] as the open boundary conditions. The analysis was based on the model result of the fine grid domain from model year 6 . The velocities and elevations at the boundaries of the parent domain were based on the geostrophic and hydrostatic equations [21].

\section{Evidence of Upwelling}

\subsection{Evidence from Cruise}

The vertical distributions of temperature along both T2 and T3 showed strong stratification at $20 \mathrm{~m}$ depth for the near-coastal stations. Meanwhile, the thermocline in the offshore area (east of $104.2^{\circ} \mathrm{E}$ ) was seen below $40 \mathrm{~m}$ depth, indicating a relatively deep, well mixed layer for a shallow shelf sea (Figure 2). In between, thermocline uplifting can be seen at $104.2^{\circ} \mathrm{E}$ (consistently throughout all transects), with a rapid drop of temperature profile towards the onshore. Similar features can also be observed in the vertical distribution of salinity.

Thermocline uplifting is a major feature related to upwelling, even though, in this situation, the thermocline did not reach the surface. The influence of strong low-salinity coastal water (32.2 - 32.8 psu) can be seen between 15 - $20 \mathrm{~m}$ (Figure 2). This coastal stratification is believed to have prevented the upwelling from reaching the surface. On the other hand, scarce data on nutrients and chlorophyll were also collected during the cruises (not shown here), and the data also show similar features. Values of phosphate, nitrite and fluorescence increased inshore from longitude $104.2^{\circ} \mathrm{E}$, almost consistent with the uplifting feature seen from the temperature and salinity cross-section. This is another indication of subsurface water being displaced upward as part of an upwelling process.

\subsection{Evidence from Remote Sensing Data}

In the 10 years of monthly-mean MODIS SST images from June to September, the most noticeable feature was the cooler water band parallel to the PM coastline at $104^{\circ} \mathrm{E}$ (Figure 3). The cooler band of water started to ap- 

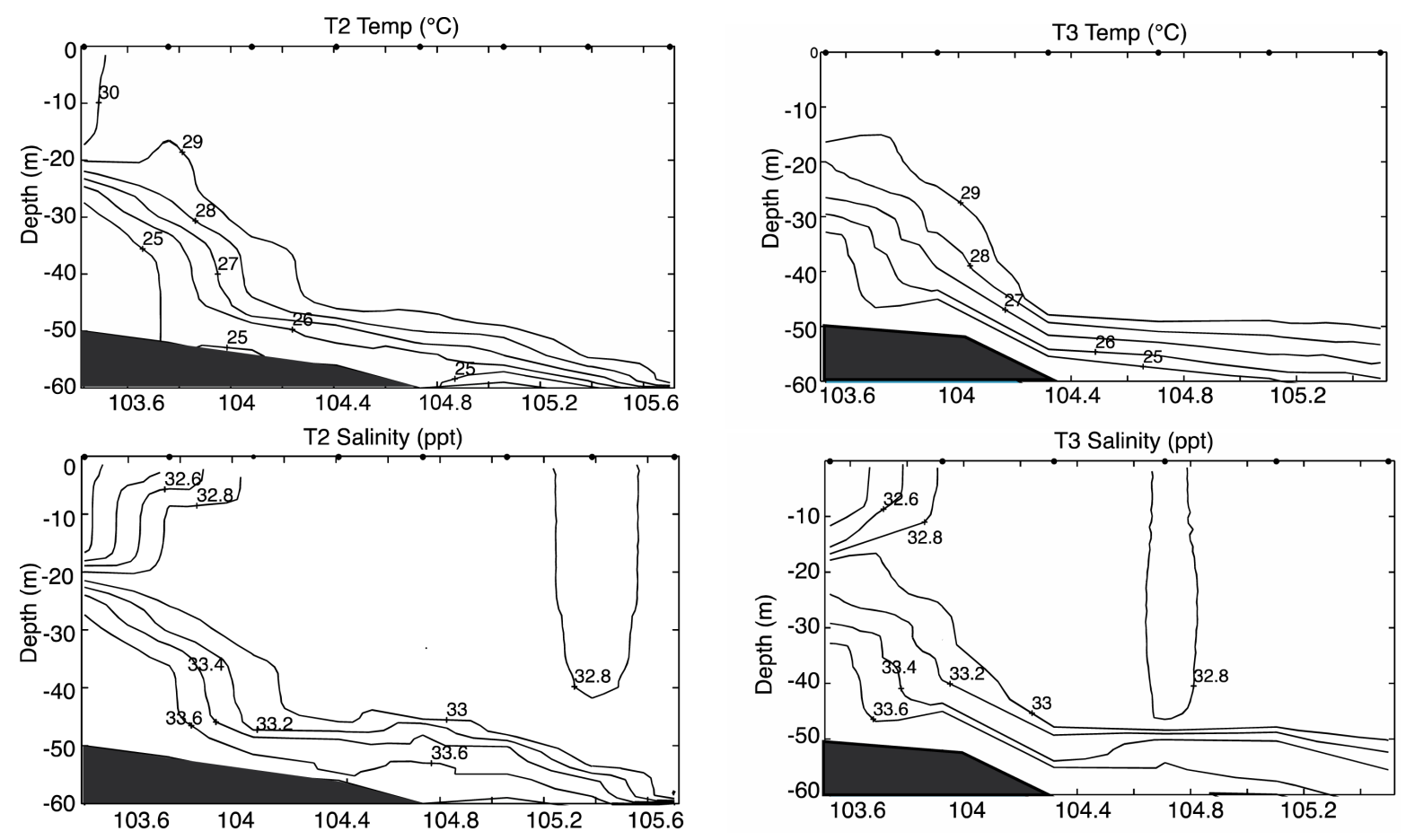

Figure 2. Vertical distributions of temperature (upper panels) and salinity (lower panels) from Transect 2 (T2) and Transect 3 (T3).
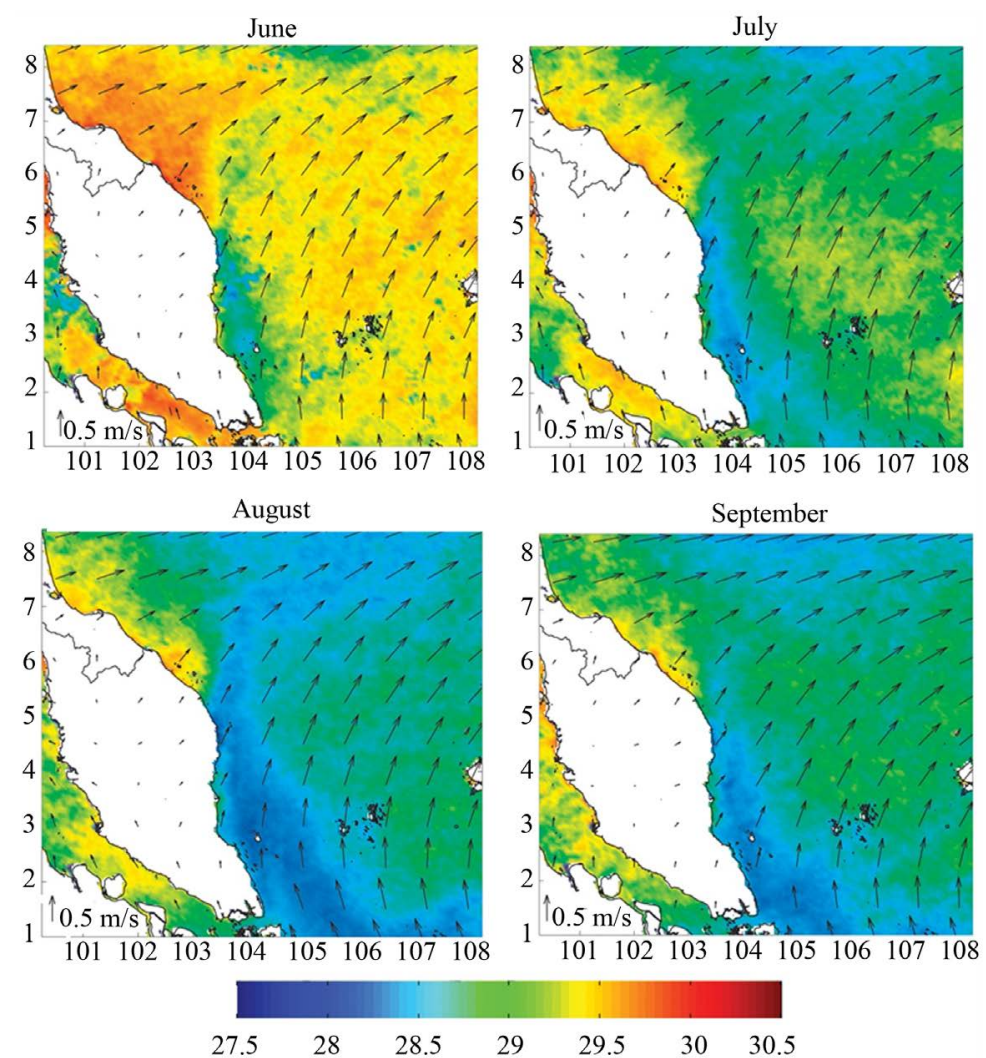

Figure 3. Monthly-mean MODIS SST $\left({ }^{\circ} \mathrm{C}\right.$; shadings) of 2002-2012, superimposed with monthly-mean wind (arrows) from the ECMWF. 
pear during June. During July and August, the band's width increased and become more prominent at the area of $3^{\circ}-4^{\circ} \mathrm{N}$, before decaying in September. The band stretched from the southernmost tip of PM until $6^{\circ} \mathrm{N}$. This is fairly consistent with the location of the thermocline uplifting from the in-situ data. This upwelling feature was very close to the coast except in the north near the Terengganu coast $\left(6^{\circ} \mathrm{N}\right)$, reaching more than $100 \mathrm{~km}$ from the coastline, again consistent with the in-situ data.

The range of SST is very small given the location of the region is near the equator, where the subsurface water is relatively warmer. Additionally, we find that the monthly-mean SST averaged over the 10 years was always warmer (cooler) than the minimum (maximum) SST in each annual cycle. Therefore, it is reasonable to expect much stronger SST gradients off PM in the real-time satellite images.

\subsection{Confirmation by Numerical Model Simulation}

The model results confirmed the presence of upwelling along the PM east coast. A comparison between the modeled SST and remote sensing data during the month of July suggests that the model performs well in showing a similar temperature distribution along the PM coast. The circulation from the model's seasonal average shows a typical northward boundary current along the PM coast during the southwest monsoon (Figure 4). The cooler SST is clearly visible at the same location of the boundary current. Since the current and low SST coincides, there is a possibility that the cooler water was brought in by advection from the south. However, both MODIS SST (Figure 3) and model output (Figure 4) show that the cooler SST is not continuous; it is isolated and stretches from $1.5^{\circ}$ to $6^{\circ} \mathrm{N}$.

Analysis of the vertical velocity along the cross section indicates active upward movement at $104^{\circ} \mathrm{E}$ (Figure 5). Comparison of temperature cross-sections from the model snapshot and in-situ data shows that uplifting of the thermocline is also located at a similar longitude and agrees with the maximum upward movement.

\section{Discussions and Conclusion}

Our study reveals the existence of a large coastal upwelling system during the southwest monsoon (summer) along the PM coast within the Sunda shelf that spans an along-shore distance of almost $650 \mathrm{~km}$, that is, from Johor to the Terengganu coast. The in-situ data, MODIS SST data and numerical model output all provided comprehensive views of this upwelling, documented for the first time. An isolated low SST band is a classical and practical indicator of upwelling, and the temperature range of $0.6^{\circ} \mathrm{C}-1^{\circ} \mathrm{C}$ between the upwelling area and the surrounding water found in the study is similar to the upwelling region reported in the central and northern SCS, i.e. the Vietnam coast and Hainan Island [1] [4] [5]. Seasonal averaged (July-September) SST from the numerical model is very similar in width and length to the MODIS SST's in June and July when a low SST band lies at $104^{\circ} \mathrm{E}$. The band became narrower further north and away from the coastline. This is probably due to wind direction and the current system, which moves northeastward in the northern part of the study area.
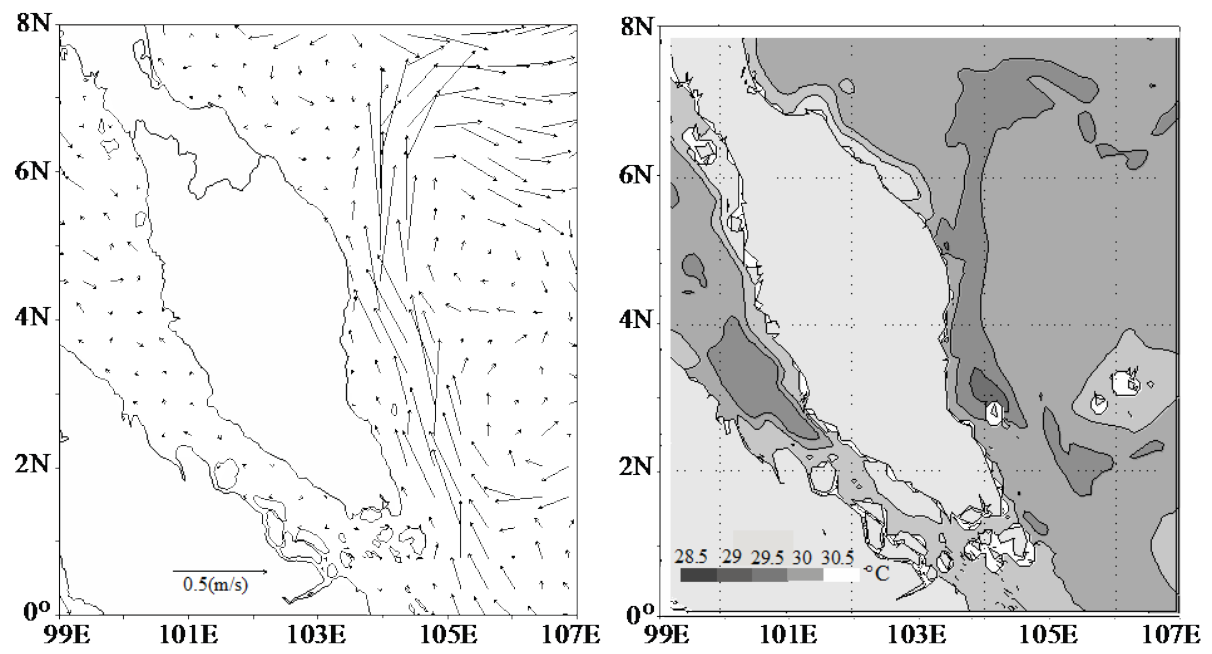

Figure 4. Surface circulations and SST averaged (June-September) distribution from the model. 


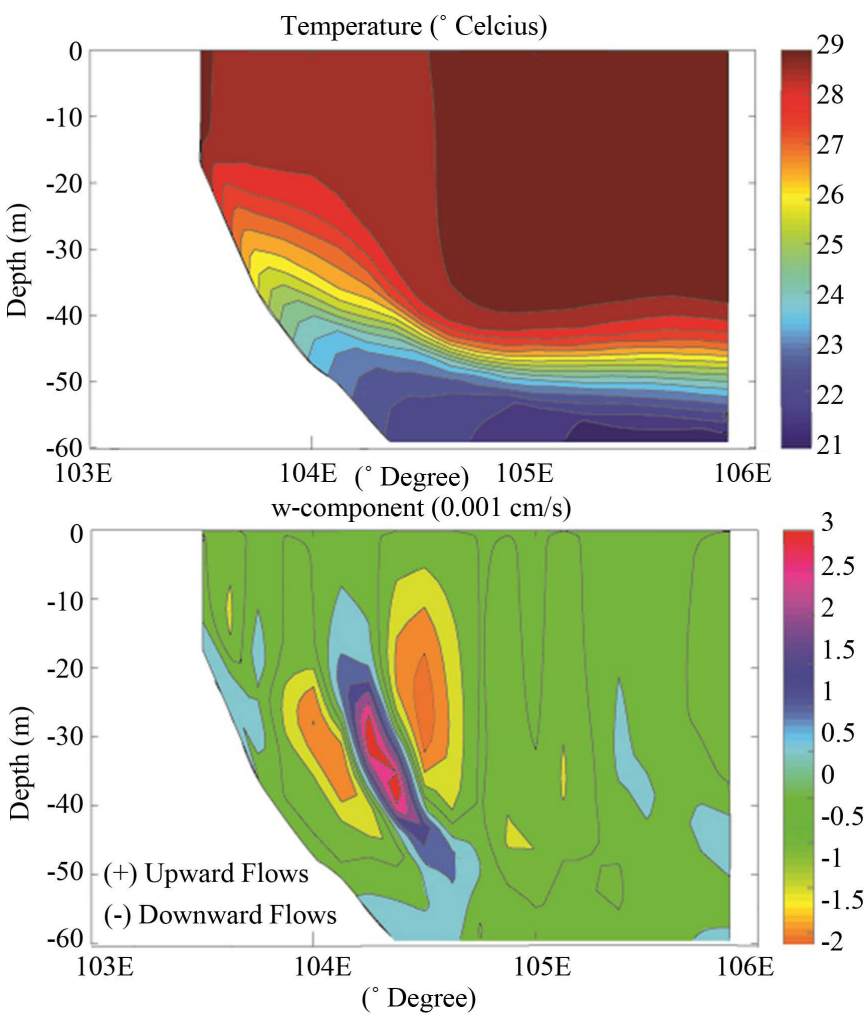

Figure 5. Cross-sections of temperature $\left({ }^{\circ} \mathrm{C}\right)$ and vertical velocity from the numerical model along a section similar to T3.

In reference to the in-situ data, the presence of low-salinity water has formed a coastal front. This low-salinity water is believed to originate locally as shown by [11]. Although upwelling at the lower part of PM is very close to the coast, in-situ data showed upwelling at the upper part was further away from the coast ( 100 km). This has very much to do with change of coastline orientation, wind stress and current direction. The boundary current maintains its northward direction at $\sim 104^{\circ}-105^{\circ} \mathrm{E}$ before it diverts near $6^{\circ} \mathrm{N}$ northeastward towards the Vietnam coast, as reported in previous studies [14] [22]. This diversion is also visible from the SST at the upper part of PM, where cooler water spreads northeastward (Figure 4).

The in-situ data clearly demonstrate the uplifting of thermocline layer, nonetheless the thermocline lift did not reach to the surface. The presence of a low-salinity coastal front is believed to be one of the reasons (Figure 2). Other literature stated that a high atmospheric heatflux [5] and wind variation [23] can also be the factors. In fact, wind data onboard the ship showed inconsistent wind direction during the cruise (not shown), which probably contributed to the weakened upwelling strength.

In this study, we found that the upwelling revealed by the in-situ data is actually only part of a larger upwelling system along the PM coast. Additionally, the southwest monsoon induces upwelling off the PM east coast, which is in ccordance with the Ekman upwelling theory. Nevertheless, it is out of the study scope to conclude that this is the main or only factor influencing upwelling in the area. Most importantly, this study provides new insights regarding southwest monsoon dynamics that produce an upwelling system, which is known to be a particularly nutrient rich and high productivity process. It will best serve as the basis for future research in the area.

\section{Acknowledgements}

Assistance and cooperation of the captain and crew of the KL Cermin (Malaysia Fisheries Institute) are gratefully acknowledged. This study was supported by the Science Fund, MOSTI (SF 04-01-12-SF0097 \&), the Higher Institution Centre of Excellence (HICoE) Fund, the Long Term Research Grant (LRGS/TD/2011/UKM/PG/ 01) and the international cooperation project of the Ocean Forecast System under UNESCO/IOC, supported by the State Oceanic Administration, China. 


\section{References}

[1] Chen, C., Lai, Z., Beardsley, R.C., et al. (2012) Current Separation and Upwelling over the Southeast Shelf of Vietnam in the South China Sea. Journal of Geophysical Research, 117. http://dx.doi.org/10.1029/2011JC007150

[2] Kuo, N.J., Zheng, Q. and Ho, C.R. (2000) Satellite Observation of Upwelling along the Western Coast of the South China Sea. Remote Sensing of Environment, 74, 463-470. http://dx.doi.org/10.1016/s0034-4257(00)00138-3

[3] Xie, S.P., Xie, Q., Wang, D. and Liu, W.T. (2003) Summer Upwelling in the South China Sea and Its Role in Regional Climate Variations. Journal of Geophysical Research, 108, 1-13. http://dx.doi.org/10.1029/2003JC001867

[4] Lü, X., Qiao, F., Wang, G., et al. (2008) Upwelling off the West Coast of Hainan Island in Summer: Its Detection and Mechanisms. Geophysical Research Letters, 35, Article ID: L02604. http://dx.doi.org/10.1029/2007GL032440

[5] Su, J. and Pohlmann, T. (2009) Wind and Topography Influence on an Upwelling System at the Eastern Hainan Coast. Journal of Geophysical Research, 114, Article ID: C06017. http://dx.doi.org/10.1029/2008JC005018

[6] Liong, P.C. (1974) Hydrographic Condition off East Coast of Peninsular Malaysia during August 1972, Malaysian. Agriculture Journal, 49, 492-513.

[7] Marghany, M. and Hussien, M.L. (2003) Upwelling and Downwelling along the Coastal Waters of Kuala Terengganu. Ultra Scientist of Physical Sciences, 15, 201-208. http://ultrascientist.org/JUSPS/15(2)/1.htm

[8] Dippner, J.W., Nguyen, K.V., Hein, H., Ohde, T. and Loick, N. (2007) Monsoon-Induced Upwelling off the Vietnamese Coast. Ocean Dynamics, 57, 46-62. http://dx.doi.org/10.1007/s10236-006-0091-0

[9] Dale, W.L. (1956) Wind and Drift Currents in the South China Sea. The Malaysian Journal of Tropical Geography, 8, $1-31$.

[10] Wyrtki, K. (1961) Scientific Results of Marine Investigations of the South China Sea and the Gulf of Thailand 1959-1961. Naga Report 2.

[11] Yanagi, T., Sachoemar, S.I., Takao, T. and Fujiwara, S. (2001) Seasonal Variation of Stratification in the Gulf of Thailand. Journal of Oceanography, 57, 461-470. http://dx.doi.org/10.1023/A:1021237721368

[12] Fang, W., Fang, G., Shi, P. and Huang, Q. (2002) Seasonal Structures of Upper Layer Circulation in the Southern South China Sea from in Situ Observations. Journal of Geophysical Research, 107, 1-12. http://dx.doi.org/10.1029/2002JC001343

[13] Akhir, M.F. (2012) Surface Circulation and Temperature Distribution of Southern South China Sea from Global Ocean Model (OCCAM). Sains Malaysiana, 41, 701-714.

[14] Tangang, F.T., Xia, C., Qiao, F., et al. (2011) Seasonal Circulations in the Malay Peninsula Eastern Continental Shelf from a Wave-Tide-Circulation Coupled Model. Ocean Dynamics, 61, 1317-1328. http://dx.doi.org/10.1007/s10236-011-0432-5

[15] Smith, W.H. and Sandwell, D.T. (1997) Global Sea Floor Topography from Satellite Altimetry and Ship Depth Soundings. Science, 277, 1956-1962. http://dx.doi.org/10.1126/science.277.5334.1956

[16] Penven, P., Marchesiello, P., Debreu, L. and Lefèvre, J. (2008) Software Tools for Pre- and Post-Processing of Oceanic Regional Simulations. Environmental Modelling \& Software, 23, 660-662.

http://dx.doi.org/10.1016/j.envsoft.2007.07.004

[17] Da Silva, A.M., Young, C.C. and Levitus, S. (1994) Atlas of Surface Marine Data 1994, Vol. 1, Algorithms and Procedures. NOAA Atlas NESDIS 6, U.S. Department of Commerce, NOAA, NESDIS, USA.

[18] Berliand, M.E. and Berliand, T.G. (1952) Measurement of the Effective Radiation of the Earth with Varying Cloud Amounts. Izv. Akad. Nauk SSR, Ser. Geofiz., 1, 64-78. (In Russian)

[19] Large, W.G., McWilliams, J.C. and Doney, S.C. (1994) A Review and Model with a Nonlocal Boundary Layer Parameterization. Reviews of Geophysics, 32, 363-403. http://dx.doi.org/10.1029/94RG01872

[20] Locarnini, R.A., Mishonov, A.V., Antonov, J.I., et al. (2006) World Ocean Atlas 2005, Volume 1: Temperature. In: Levitus, S., Ed., NOAA Atlas NESDIS 61, U.S. Government Printing Office, Washington DC.

[21] Marchesiello, P., McWilliams, J.C. and Shchepetkin, A. (2001) Open Boundary Conditions for Long-Term Integration of Regional Oceanic Models. Ocean Modelling, 3, 1-20. http://dx.doi.org/10.1016/S1463-5003(00)00013-5

[22] Chu, P.C., Edmons, N.L. and Fan, C. (1999) Dynamical Mechanisms for the South China Sea Seasonal Circulation and ThermohalineVariabilities. Journal of Physical Oceanography, 29, 2971-2989. http://dx.doi.org/10.1175/1520-0485(1999)029<2971:DMFTSC>2.0.CO;2

[23] Kämpf, J. (2004) Evidence of a Large Seasonal Coastal Upwelling System along the Southern Shelf of Australia. Geophysical Research Letters, 31, Article ID: L09310. http://dx.doi.org/10.1029/2003gl019221 